\title{
Balanço do nitrogênio e fósforo em solo com cultivo orgânico de hortaliças após a incorporação de biomassa de guandu
}

\author{
Sandra Maria Campos Alves ${ }^{(1)}$, Antonio Carlos de Souza Abboud(2), Raul de Lucena Duarte Ribeiro(2) \\ e Dejair Lopes de Almeida ${ }^{(3)}$
}

\begin{abstract}
(1)Universidade de São Paulo, Escola Superior de Agricultura Luiz de Queiroz, Caixa Postal 9, CEP 13418-900 Piracicaba, SP. E-mail: smcalves@ciagri.usp.br (2)Universidade Federal Rural do Rio de Janeiro, Instituto de Agronomia, BR 465, Km 47, CEP 23890-000 Seropédica, RJ. E-mail: abboud@ufrrj.br, raul@ufrrj.br ${ }^{(3)}$ Embrapa Agrobiologia, BR 465, Km 47, CEP 23890-000 Seropédica, RJ. E-mail: dejair@cnpab.embrapa.br
\end{abstract}

\begin{abstract}
Resumo - Os objetivos deste trabalho foram avaliar os efeitos de faixas de guandu (Cajanus cajan) e da incorporação da biomassa proveniente de sua poda na fertilidade do solo e na produtividade de três hortaliças sob cultivo orgânico. O delineamento usado foi de blocos casualizados completos em esquema de parcelas subsubdivididas com três repetições. As produtividades de beterraba, cenoura e feijão-de-vagem não foram afetadas pelos tratamentos. Nas parcelas onde não houve incorporação da biomassa de guandu, o balanço de nitrogênio no sistema foi negativo, ao passo que com a incorporação, esse balanço foi positivo. Embora tenha ocorrido balanço positivo para o fósforo nas parcelas sem a incorporação de biomassa de guandu, houve um aumento significativo na absorção desse elemento pelas hortaliças quando o material foi incorporado. $\mathrm{O}$ sistema de cultivo em aléias de guandu pode representar uma prática vantajosa para os produtores orgânicos, por contribuir na manutenção da fertilidade do solo.
\end{abstract}

Termos para indexação: Cajanus cajan, agricultura orgânica, hortaliça, adubo verde, nutriente, fertilidade do solo.

\section{Nitrogen and phosphorus balance in soil with organic cultivation of legumes after incorporation of pigeonpea biomass}

\begin{abstract}
The objectives of this study were to evaluate the efficiency of pigeonpea (Cajanus cajan) biomass incorporation to the soil as well as the effect of presence or absence of pigeonpea hedgerows on soil fertility and productivity of three vegetables, beet, carrot and dwarf green bean. Samples were randomly taken in a block design with three replications for each crop. In the field, no other fertilization treatment was applied. In plots without biomass incorporation, nitrogen showed negative balance, whereas in the field with biomass incorporation a high positive N-balance was found. Concerning phosphorus, positive balances were determined in plots without biomass incorporation, however, the uptake of $\mathrm{P}$ increased significantly after biomass incorporation in all crops used. The results indicate that pigeonpea alley cropping system may represent an advantageous option for organic farmers to maintain or to improve soil fertility.
\end{abstract}

Index terms: Cajanus cajan, organic agriculture, vegetables, green manures, nutrients, soil fertility.

\section{Introdução}

A produção orgânica de hortaliças tem crescido significativamente nos últimos anos, na Região Sudeste do Brasil. O mercado emergente desses produtos tem feito com que muitos agricultores convencionais passem a adotar o sistema orgânico. Com a recente legislação que normatiza essa forma de produção (Brasil, 1999, 2001), novos sistemas agroecológicos necessitam ser criados a fim de atender à crescente demanda de credenciamento e certificação de estabelecimentos rurais.
Freqüentemente, grandes quantidades de esterco animal, composto ou outros fertilizantes orgânicos são usadas em sistemas intensivos de produção de hortaliças, sem necessariamente, se conhecer o balanço dos nutrientes em cada situação. Apesar da preocupação com a manutenção da fertilidade do solo, os sistemas orgânicos de produção, na maioria das vezes, ignoram ou subestimam a possibilidade de integração entre hortaliças e outras espécies de plantas em consórcios, com múltiplas finalidades. 
A inclusão de leguminosas arbustivas ou arbóreas pode representar excelente opção para diversificar sistemas agrícolas intensivos. Essas espécies são capazes de fixar consideráveis quantidades de $\mathrm{N}$ do ar, além de acumular na sua biomassa nutrientes originários de locais não acessíveis às hortaliças. Por serem plantas perenes e rústicas, as leguminosas dinamizam a ciclagem dos nutrientes (Zaraharah et al., 1999), durante períodos em que muitas das hortaliças não podem ser cultivadas por limitação de temperatura ou umidade. Podem, ainda, prover sombra e proteger contra ventos, criando um microclima favorável (Koech \& Whitbread, 2000), com impactos positivos na economia de água, na proteção contra pragas e doenças, e no controle da erosão laminar. Servem também de abrigo, produzindo pólen e néctar em benefício de inimigos naturais, além de auxiliar a redução de infestação por plantas indesejáveis da vegetação espontânea.

Uma forma viável de integração dessas leguminosas em sistemas orgânicos de produção é o cultivo em aléias. Nesse sistema, faixas de leguminosas são estabelecidas, recebendo podas periódicas, que devem ser sincronizadas com o ciclo de plantas de interesse comercial cultivadas entre essas faixas. Vários autores relatam os efeitos benéficos dos sistemas de cultivo em aléias na fertilidade do solo, controle de erosão, matéria orgânica e N do solo (Kang et al., 1984, 1995; Yamoah et al., 1986; Kass et al., 1989; Quinton \& Rodriguez, 1999; McDonald et al., 2003; Tangya et al., 2003). A eficiência desses sistemas depende da sincronização entre a ciclagem dos nutrientes e as fases de maior absorção pelas culturas, da fixação biológica do $\mathrm{N}_{2}$ e do suprimento de nutrientes pelos resíduos da poda da leguminosa consorciada.

$\mathrm{O}$ cultivo em aléias tem sido pesquisado em várias partes do mundo, principalmente para cereais, como arroz (Danso \& Mogan, 1998), milho (Brewbaker, 1985) e sorgo (Matta-Machado et al., 1994); hortaliças, como tomateiro e jiloeiro (Palada et al., 1992), "kenaf" (Gutteridge, 1988), repolho e couve (Mapaona \& Kitou, 1994), feijão (Mafra et al., 1998) e "mulberry" (Tangya et al., 2003). No Brasil, entretanto, poucos estudos foram realizados nesse campo (Riley \& Smyth, 1993).

O guandu (Cajanus cajan L.) é uma leguminosa tropical fixadora de grande quantidade de $\mathrm{N}$ atmosférico, que se adapta a diferentes condições ambientais. É comumente usada como adubo verde, quebra-ventos, forragem e alimento humano. Trata-se de uma espécie amplamente difundida em pequenos estabelecimentos rurais no Brasil, oferecendo a possibilidade tanto de con- sumo dos grãos como de comercialização em mercados locais. Torna-se, assim, uma espécie adequada para integrar sistemas de produção de hortaliças com base agroecológica.

Os objetivos deste trabalho foram avaliar os efeitos de faixas de guandu (Cajanus cajan) e da incorporação da biomassa proveniente de sua poda na fertilidade do solo e na produtividade de três hortaliças sob cultivo orgânico.

\section{Material e Métodos}

O trabalho foi realizado no Sipa (Sistema Integrado de Pesquisa em Produção Agroecológica), numa área de pesquisa e produção em agricultura orgânica, situada no Km 47 da antiga Rio-São Paulo, Seropédica, RJ $\left(22^{\circ} 45^{\prime} \mathrm{S}\right.$ e $43^{\circ} 42^{\prime} \mathrm{W} ; 33 \mathrm{~m}$ de altitude). O solo foi classificado como Argissolo Vermelho-Amarelo (Embrapa, 1999).

Antes da instalação do experimento, foram coletadas, de forma aleatória, amostras de solo, na profundidade de 0-10 cm, na área experimental, com manejo sob sistema orgânico por mais de cinco anos. Ao todo foram 12 amostras compostas sendo cada uma formada de cinco subamostras. Os resultados médios da análise química dessas amostras foram: $\mathrm{pH}$ (água), 6,2; carbono orgânico, $0,67 \% ; \mathrm{Al}^{+3}, 0,0 \mathrm{cmol}_{\mathrm{c}} \mathrm{dm}^{-3} ; \mathrm{Ca}^{2+}, 4,5 \mathrm{cmol}_{\mathrm{c}} \mathrm{dm}^{-3}$; $\mathrm{Mg}^{2+}, 2,5 \mathrm{cmol}_{\mathrm{c}} \mathrm{dm}^{-3}$; $\mathrm{P}, 1,6 \mathrm{mg} \mathrm{dm}^{-3}$; $\mathrm{e} \mathrm{K}^{+}, 110,6 \mathrm{mg} \mathrm{dm}^{-3}$. Procedeu-se a divisão do experimento em blocos casualizados, com dois tratamentos, no esquema de parcelas subsubdivididas com três repetições. Os tratamentos das parcelas constituíram-se da presença ou ausência de faixas de guandu. Os tratamentos das subparcelas foram com e sem incorporação de biomassa de guandu. $\mathrm{Na}$ subparcela com incorporação de guandu onde essa planta não foi cultivada foi incorporado o material retirado da subparcela sem incorporação de guandu onde ele havia sido cultivado.

Cada subparcela foi dividida e numa das metades cultivou-se cenoura e na outra, beterraba seguida de feijão-de-vagem. O ciclo da cenoura equivaleu à soma dos ciclos das outras duas hortaliças.

Antes do plantio de cenoura e beterraba, aplicaramse $15 \mathrm{~kg} \mathrm{ha}^{-1}$ de $\mathrm{P}_{2} \mathrm{O}_{5}$ (termofosfato sílico-magnesiano) e $20 \mathrm{t} \mathrm{ha}^{-1}$ de esterco bovino curtido, com a seguinte composição: $1,36 \%$ de $\mathrm{N} ; 0,44 \%$ de $\mathrm{P} ; 0,50 \%$ de $\mathrm{K}$; $0,74 \%$ de $\mathrm{Ca} ; 0,21 \%$ de $\mathrm{Mg} ; 0,12 \%$ de $\mathrm{S} ; 68 \mathrm{mg} \mathrm{kg}^{-1} \mathrm{de}$ B; $42 \mathrm{mg} \mathrm{kg}^{-1}$ de Cu; $1.438 \mathrm{mg} \mathrm{kg}^{-1}$ de Fe; $94 \mathrm{mg} \mathrm{kg}^{-1}$ de Mn e $379 \mathrm{mg} \mathrm{kg}^{-1}$ de zinco. A cenoura cultivar Brasília 
foi semeada no campo em 17/5/1998 no espaçamento de $0,20 \times 0,05 \mathrm{~m}$. A beterraba cultivar Rosette foi semeada em bandejas de 200 células, em casa de vegetação, e transplantada para o campo 21 dias após a emergência (no mesmo dia da semeadura da cenoura), no espaçamento de $0,20 \mathrm{x} 0,20 \mathrm{~m}$, compondo seis linhas com comprimento de 9,6 m. O feijão-de-vagem cultivar Alessa foi semeado em 10/6/1998, após a colheita da beterraba, no espaçamento de $0,25 \times 0,20 \mathrm{~m}$, compondo cinco linhas. Foram feitas três capinas manuais, não se fazendo uso de qualquer tratamento fitossanitário ou fertilizante solúvel.

A beterraba foi colhida nas quatro linhas centrais do canteiro de cada parcela, desprezando duas linhas da bordadura, e as raízes foram lavadas e separadas em comercializáveis e não comercializáveis. Foram consideradas como comercializáveis as raízes sem rachaduras ou deformações; a cenoura foi colhida das quatro fileiras centrais de cada parcela, sendo as raízes lavadas e separadas em comercializáveis e não comercializáveis; quanto ao feijão-de-vagem, foram colhidas as três linhas centrais de cada parcela em razão do menor espaçamento desta cultura em relação às anteriores, desprezando-se as bordaduras. As vagens foram retiradas das plantas e pesadas, após eliminação dos refugos - tamanho insuficiente e defeitos de natureza diversa. Foram também determinados o número e a massa dos nódulos bacterianos radiculares de três plantas por parcela, tomadas ao acaso.

Para se conhecer o fluxo de nutrientes no sistema estudado, calcularam-se os balanços simples de $\mathrm{N}$ e $\mathrm{P}$, considerando-se o fornecimento proveniente de esterco, termofosfato e biomassa podada de guandu, e os nutrientes exportados com os produtos colhidos (raízes de beterraba e cenoura e frutos de feijão-de-vagem).

Os teores de $\mathrm{N}$ e $\mathrm{P}$ foram determinados em extratos líquidos obtidos da digestão do material vegetal com ácido sulfúrico e peróxido de hidrogênio. $\mathrm{O} \mathrm{N}$ foi determinado por destilação a vapor (Kjeldahl) e o P, colorimetricamente, conforme Tedesco (1982).

\section{Resultados e Discussão}

A biomassa oriunda das faixas de guandu após a poda alcançou a média de $11 \mathrm{t} \mathrm{ha}^{-1}$ de matéria seca, contendo 283 e $23 \mathrm{~kg} \mathrm{ha}^{-1}$ de $\mathrm{N}$ e P, respectivamente. Durante o ciclo das hortaliças, as faixas podadas de guandu retomaram o crescimento, a ponto de sombrear as parcelas pela manhã e à tarde. Esse sombreamento não influen- ciou a produtividade das espécies estudadas (Tabela 1). A incorporação da biomassa podada também não interferiu na produção comercial das culturas.

A produtividade da beterraba foi inferior à obtida anteriormente na região (Almeida, 1991). Franch (2000) já havia indicado menor produtividade do híbrido Rosette sob cultivo orgânico, em relação às outras cultivares atualmente disponíveis no mercado. Não houve efeito interativo de presença ou ausência de faixas e incorporação ou não-incorporação de biomassa de guandu, quanto à produção de raízes comercializáveis de beterraba (Tabela 2). A incorporação da biomassa procedente da

Tabela 1. Efeito da presença ou ausência de faixas de guandu e da incorporação ou não da respectiva biomassa proveniente da poda, na produção comercializável de beterraba, cenoura e feijão-de-vagem ${ }^{(1)}$.

\begin{tabular}{lccc}
\hline Biomassa & $\begin{array}{c}\text { Beterraba } \\
\text { (raízes) }\end{array}$ & $\begin{array}{c}\text { Cenoura } \\
(\text { raízes })\end{array}$ & $\begin{array}{c}\text { Feijão-de-vagem } \\
\text { (vagens) }\end{array}$ \\
\hline $\begin{array}{l}\text { Com incorporação } \\
\text { da biomassa }\end{array}$ & $22,90 \mathrm{a}$ & $69,10 \mathrm{a}$ & $6,80 \mathrm{a}$ \\
$\begin{array}{l}\text { Sem incorporação } \\
\text { da biomassa }\end{array}$ & $19,50 \mathrm{a}$ & $70,40 \mathrm{a}$ & $6,00 \mathrm{a}$ \\
\hline $\begin{array}{l}\text { Com incorporação } \\
\text { da biomassa }\end{array}$ & \multicolumn{2}{c}{ Ausência de faixas de guandu } & \\
$\begin{array}{l}\text { Sem incorporação } \\
\text { da biomassa }\end{array}$ & $21,50 \mathrm{a}$ & $70,00 \mathrm{a}$ & $6,70 \mathrm{a}$ \\
\hline
\end{tabular}

${ }^{(1)}$ Médias seguidas pela mesma letra, tanto na presença como na ausência de faixas de guandu, não diferem entre si pelo teste de Tukey a 5\% de probabilidade.

Tabela 2. Efeito da presença ou ausência de faixas de guandu e da incorporação ou não da respectiva biomassa proveniente da poda, na produção de raízes comercializáveis de beterraba, e de nódulos secos de feijão-de-vagem ${ }^{(1)}$.

\begin{tabular}{lcc}
\hline Biomassa & $\begin{array}{c}\text { Raízes de } \\
\text { beterraba } \\
\text { (g por planta) }\end{array}$ & $\begin{array}{c}\text { Nódulos secos } \\
\text { de feijão-de-vagem } \\
\text { (mg por planta) }\end{array}$ \\
\hline $\begin{array}{l}\text { Com incorporação } \\
\text { da biomassa }\end{array}$ & $146,80 \mathrm{a}$ & $37,00 \mathrm{bA}$ \\
$\begin{array}{l}\text { Sem incorporação } \\
\text { da biomassa }\end{array}$ & $110,14 \mathrm{a}$ & $74,00 \mathrm{aA}$ \\
\hline $\begin{array}{l}\text { Com incorporação } \\
\text { da biomassa }\end{array}$ & Ausência de faixas de guandu \\
$\begin{array}{l}\text { Sem incorporação } \\
\text { da biomassa }\end{array}$ & $126,40 \mathrm{a}$ & $145,00 \mathrm{aA}$ \\
\hline
\end{tabular}

${ }^{(1)}$ Médias seguidas pela mesma letra minúscula, tanto na presença como na ausência de faixas de guandu, não diferem entre si pelo teste de Tukey a 5\% de probabilidade; médias seguidas da mesma letra maiúscula não diferem entre si quanto à incorporação ou não da biomassa do guandu na presença ou na ausência de faixas de guandu, pelo teste de Tukey a $5 \%$ de probabilidade. 
poda do guandu aumentou a massa dessas raízes em $33 \%$.

A produtividade da cenoura não apresentou diferença significativa em relação ao efeito do sistema de faixas ou da incorporação de fitomassa (Tabela 1). A porcentagem de raízes comercializáveis foi elevada e a produtividade atingiu $70 \mathrm{tha}^{-1}$ na área com faixa de guandu e sem incorporação de biomassa, com massa de raízes entre 120 e 160 g por planta nos quatro tratamentos. Em estudo realizado no mesmo local, Sudo et al. (1997) reportaram, quanto à cultivar Brasília, sob manejo orgânico, produtividades de $40 \mathrm{t} \mathrm{ha}^{-1}$ e massa média de raízes de apenas $59 \mathrm{~g}$ por planta. Ainda em relação à cenoura Brasília, em monocultivo convencional, Ritschel et al. (1995) computaram médias de $75 \mathrm{~g}$ de raízes por planta, e Caetano et al. (1997) obtiveram 41 t ha-1 . Já Souza (1998), em sistema orgânico de produção, obteve até $53 \mathrm{t} \mathrm{ha}^{-1}$, trabalhando com a mesma cultivar.

A produtividade do feijão-de-vagem também não foi afetada pelos tratamentos, apesar do efeito significativo verificado na presença das faixas de guandu na massa de nódulos (Tabela 2). Houve interação significativa entre faixas e incorporação da biomassa podada quanto à nodulação. Na presença das faixas, a incorporação teve efeito negativo, enquanto na ausência delas, tal fato não ocorreu.

Apesar de a nodulação ter sido reduzida, a quantidade de $\mathrm{N}$ acumulada não foi afetada, ou seja, houve efeito compensatório no sistema com queda na fixação biológica de N (FBN) pelo feijão-de-vagem. Provavelmente a presença de faixas teria propiciado condição favorável à acumulação de N, limitando a fixação biológica do $\mathrm{N}$ atmosférico. Outros autores já concluíram que a FBN é reduzida em solo com boa condição de fertilidade (Döbereiner et al., 1966; Franco et al., 1978).
Cultivos em aléias teriam como desvantagem a diminuição da área explorada, que é ocupada pelas faixas da espécie arbustiva. Neste trabalho, descontando a área correspondente às faixas duplas de guandu e recalculando os valores, as produtividades permaneceram elevadas (beterraba, $15 \mathrm{t} \mathrm{ha}^{-1}$; cenoura, $50 \mathrm{t} \mathrm{ha}^{-1} \mathrm{e}$ feijão-de-vagem, $\left.5 \mathrm{t} \mathrm{ha}^{-1}\right)$.

Essas altas produtividades, assim como a alta produção de biomassa pelo guandu, explicariam a ausência de resposta aos tratamentos, em relação à maioria das variáveis avaliadas, constituindo-se um indicativo de que o sistema já se encontrava com solo fértil, já que o trabalho foi realizado dentro de um sistema integrado que vem recebendo manejo orgânico por seis anos. Os níveis de fertilidade alcançados, muitas vezes, não permitem respostas significativas à aplicação de nutrientes (Braga, 1997; Oliveira, 2001).

$\mathrm{O}$ balanço do $\mathrm{N}$ e do $\mathrm{P}$ reciclados pela leguminosa, apesar de não terem sido totalmente originados fora da área, representam uma entrada ponderável (Tabelas 3 e 4). O N contido na biomassa do guandu foi, em parte, obtido mediante a FBN e, em parte, absorvido de uma camada ou fração do solo inacessível às hortaliças. Quanto ao P, considerando ser o guandu uma planta solubilizadora desse elemento (Ae et al., 1990), com um sistema radicular bem diferenciado e profundo, estaria também provendo uma reciclagem a partir de locais não disponíveis para as hortaliças, constituindo-se também em entrada.

No caso específico da área cultivada com beterraba seguida de feijão-de-vagem, na ausência de incorporação de biomassa de guandu, houve balanço negativo de $\mathrm{N}$ (-27 kg ha-1 de N), ao passo que, com a incorporação do material podado, esse balanço tornou-se positivo (+259 kg ha-1 de N). Um balanço negativo pode, em médio prazo, induzir diminuição da fertilidade do solo, notadamente com respeito às reservas de $\mathrm{N}$ da matéria

Tabela 3. Balanço de nitrogênio $\left(\mathrm{kg} \mathrm{ha}^{-1}\right)$ em cultivo orgânico de beterraba + feijão-de-vagem e de cenoura na presença ou ausência de faixas de guandu, com ou sem incorporação da biomassa proveniente da poda do guandu.

\begin{tabular}{|c|c|c|c|c|c|c|c|}
\hline \multirow[t]{2}{*}{ Biomassa } & \multicolumn{3}{|c|}{ Entrada de $\mathrm{N}$} & \multicolumn{2}{|c|}{ Beterraba + feijão de vagem ${ }^{(1)}$} & \multicolumn{2}{|c|}{ Cenoura $^{(2)}$} \\
\hline & Esterco bovino & Biomassa de guandu & Total & Saída de N & Balanço de $\mathrm{N}$ & Saída de N & Balanço de $\mathrm{N}$ \\
\hline & \multicolumn{7}{|c|}{ Presença de faixas de guandu } \\
\hline Com incorp. da biomassa & 67 & 283 & 350 & 102 & +248 & 57 & +293 \\
\hline Sem incorp. da biomassa & 67 & 0 & 67 & 94 & -27 & 47 & +20 \\
\hline \multicolumn{8}{|c|}{ Ausência de faixas de guandu } \\
\hline Com incorp. da biomassa & 67 & 283 & 350 & 91 & +259 & 70 & +280 \\
\hline Sem incorp. da biomassa & 67 & 0 & 67 & 77 & -10 & 67 & 0 \\
\hline
\end{tabular}

${ }^{(1)}$ O feijão-de-vagem foi cultivado após o cultivo da beterraba; de ambas as culturas, o produto colhido refere-se ao padrão comercializável. (2)Produto comercializável. 
Tabela 4. Balanço de fósforo $\left(\mathrm{kg} \mathrm{ha}^{-1}\right)$ em cultivo orgânico de beterraba, feijão-de-vagem e de cenoura na presença ou ausência de faixas de guandu, com ou sem incorporação da biomassa proveniente da poda.

\begin{tabular}{|c|c|c|c|c|c|c|c|c|}
\hline \multirow[t]{2}{*}{ Biomassa } & \multicolumn{4}{|c|}{ Entrada de $\mathrm{P}$} & \multicolumn{2}{|c|}{ Beterraba + feijão-de-vagem ${ }^{(1)}$} & \multicolumn{2}{|c|}{ Cenoura $^{(2)}$} \\
\hline & Fosfato & $\begin{array}{l}\text { Esterco } \\
\text { bovino }\end{array}$ & $\begin{array}{l}\text { Biomassa } \\
\text { de guandu }\end{array}$ & Total & $\begin{array}{l}\text { Saída } \\
\text { de P }\end{array}$ & $\begin{array}{c}\text { Balanço } \\
\text { de P }\end{array}$ & $\begin{array}{r}\text { Saída } \\
\text { de P }\end{array}$ & $\begin{array}{c}\text { Balanço } \\
\text { de P }\end{array}$ \\
\hline & \multicolumn{8}{|c|}{ Presença de faixas de guandu } \\
\hline Com incorp. da biomassa & 15 & 5 & 23 & 43 & 12 & +31 & 20 & +23 \\
\hline Sem incorp. da biomassa & 15 & 5 & 0 & 20 & 13 & +7 & 15 & +5 \\
\hline \multicolumn{9}{|c|}{ Ausência de faixas de guandu } \\
\hline Com incorp. da biomassa & 15 & 5 & 23 & 43 & 11 & +32 & 20 & +23 \\
\hline Sem incorp. da biomassa & 15 & 5 & 0 & 20 & 13 & +7 & 20 & 0 \\
\hline
\end{tabular}

(1)O feijão-de-vagem foi cultivado após o cultivo da beterraba; de ambas as culturas, o produto colhido refere-se ao padrão comercializável.

${ }^{(2)}$ Produto comercializável.

orgânica. Considerando que se trata de material vegetal depositado em superfície, de fácil decomposição no sistema, recomendam-se doses suplementares de fertilizantes, visando à manutenção do nutriente no solo. Por outro lado, um balanço positivo, como o que foi encontrado, poderia acarretar perda desse nutriente por lixiviação ou por outros processos, caso não houvesse sincronização entre mineralização e absorção pelas culturas implantadas, ou caso o sistema não o esteja imobilizando.

As faixas de guandu, planta que cresce continuamente, podem servir como dreno de N, retardando ou impedindo sua perda no sistema. Estudos com coberturas vegetais, em sistemas de rotação com hortaliças, têm demonstrado que leguminosas desenvolvendo-se no período de entressafra podem reduzir as perdas de $\mathrm{N}$ (Yaffa et al., 2000). Akonde et al. (1997), trabalhando com faixas de guandu destinadas a prover biomassa para cultivos subseqüentes de milho, constataram aumento de $131 \mathrm{~kg} \mathrm{ha}^{-1}$ de $\mathrm{N}$ no sistema.

No caso do P, o seu aumento ou decréscimo no solo depende do balanço entre as adições e as saídas. Assim, nas terras de exploração agrícola, há um declínio biológico por causa da exportação pelas colheitas, que pode ser expressivo quando as doses reaplicadas são baixas, especialmente considerando as reações com constituintes minerais, como os óxidos de ferro e alumínio, os quais ocorrem em quase todos os tipos de solo, podendo reter mais de 2/3 do $\mathrm{P}$ adicionado (McCollun, 1991).

Ainda que tenha se observado ausência de resposta à incorporação de biomassa proveniente das faixas de guandu, a situação poderia reverter-se caso o nível de fertilidade decrescesse com o tempo, já que os balanços, em relação ao $\mathrm{N}$ e $\mathrm{P}$, mostraram-se negativos ou menos positivos, respectivamente, quando a biomassa não foi incorporada. Assim, para que não haja esgotamento desses nutrientes, doses mais elevadas de insumos externos deveriam ser empregadas. Alternativamente, ao se adotar as faixas de leguminosas ter-se-ia a vantagem de consideráveis quantidades de $\mathrm{N}$ e $\mathrm{P}$ mobilizados no local, seja por meio da fixação biológica de $\mathrm{N}$, seja por meio do resgate de camadas mais profundas do solo, no caso de $\mathrm{N}$ e $\mathrm{P}$, ou pela solubilização de fosfatos (Ae et al., 1990).

\section{Conclusões}

1. Faixas de guandu com produção de $11 \mathrm{t} \mathrm{ha}^{-1}$ de matéria seca fazem circular no sistema de produção de hortaliças em aléias, $283 \mathrm{~kg} \mathrm{ha}^{-1}$ de N e $23 \mathrm{~kg} \mathrm{ha}^{-1}$ de $\mathrm{P}$, num período de cinco meses.

2. A produtividade de hortaliças sob manejo orgânico é elevada e comparável à obtida sob sistema convencional de manejo.

\section{Agradecimentos}

À Capes, pela concessão da bolsa de estudo do primeiro autor; ao Prof. Dr. Jairo Antonio Mazza (Esalq/USP), pelas sugestões apresentadas.

\section{Referências}

AE, N.; ARIHARA, K.; OKADA, K.; YOSIHARA, T.; JOHANSEN, C. Phosphorus uptake by pigeonpea and its role in cropping systems of Indian subcontinent. Science, v.248, p.477480, 1990. 
AKONDE, T.P.; KUEHNE, R.F.; STEINMUELLER, N.; LEIHNER, D.E. Alley cropping on an Ultisol in subhumid Benin part 3: nutrient budget of maize, cassava and trees. Agroforestry Systems, v.37, p.213-226, 1997.

ALMEIDA, D.L. de. Contribuição da adubação orgânica para fertilidade do solo. 1991. 192 f. Tese (Doutorado em Ciência do Solo) - Universidade Federal Rural do Rio de Janeiro, Itaguaí, 1991.

BRAGA, R.M. Monitoramento dos teores de nitrato e amônio no solo e em hortaliças produzidas sob manejo orgânico. 1997. 168p. Dissertação (Mestrado) - Universidade Federal Rural do Rio de Janeiro, Itaguaí.

BRASIL. Ministério da Agricultura e do Abastecimento. Instrução Normativa n.007, de 17 de maio de 1999. Diário Oficial [da] República Federativa do Brasil, p.5-9, 1999.

BRASIL. Ministério da Agricultura e do Abastecimento. Portaria n.17, de 10 de abril de 2001. Diário Oficial [da] República Federativa do Brasil, p.9-11, 2001.

BREWBAKER, J.L. The tropical environment of maize cultivation. In: BRANDOLINI, A.; SALAMINI, F. (Ed.). Breeding strategies for maize production improvement in the tropics. Rome: FAO, 1985. p.47-77.

CAETANO, L.C.S.; FERREIRA, J.M.; ARAÚJO, M.L. Avaliação do consórcio cenoura e alface em Campos de Goytacazes-RJ. Rio de Janeiro: PESAGRO-RIO, 1997. 5p. (Comunicado Técnico, 263).

DANSO, A.A.; MOGAN, P. Alley cropping rice (Oryza sativa var. barefita) with cassia (Cassia siamea): soil fertility and crop production. Agroforestry Systems, v.21, p.147-158, 1998.

DÖBEREINER, J.; ARRUDA, N.B. de; PENTEADO, A. de F. Avaliação da fixação do nitrogênio em leguminosas, pela regressão do nitrogênio total das plantas sobre o peso dos nódulos. Pesquisa Agropecuária Brasileira, v.1, p.233-237, 1966.

EMBRAPA. Centro Nacional de Pesquisa de Solos (Rio de Janeiro, RJ). Sistema brasileiro de classificação de solos. Brasília: Embrapa-SPI; Embrapa-CNPS, 1999. 412p.

FRANCH, C.M. de C. Sistema orgânico para produção de beterraba (Beta vulgaris L.). 2000. 133p. Dissertação (Mestrado) - Universidade Federal Rural do Rio de Janeiro, Seropédica, 2000.

FRANCO, A.A.; FONSECA, O.O.; MARRIEL, L. Efeito do nitrogênio mineral na atividade da nitrogenase e nitrato redutase durante o ciclo da soja no campo. Revista Brasileira de Ciência do Solo, v.2, p.110-114, 1978.

GUTTERIDGE, R.C. Alley cropping kenaf (Hibiscus cannabinus) with leucaena (Leucaena leucocephala) in Southeastern Queensland. Australian Journal of Experimental Agriculture, v.28, p.481484, 1988 .

KANG, B.T. Alley cropping: soil productivity and nutrient recycling. Forest Ecology and Management, v.91, p.75-82, 1997.

KANG, B.T.; GRIMME, H.; LAWSON, T. Alley cropping sequential cropped maize and cowpea with Leucaena on a sandy soil in Southern Nigeria. Plant and Soil, v.85, p.267-277, 1995.
KANG, B.T.; WILSON, G.F.; LAWSON, T.L. Alley cropping: a stable alternative to shifting cultivation. Ibadan: International Institute of Tropical Agriculture, 1984. 16p.

KASS, D.; BARRANTES, W.; CAMPOS, W.; JIMÉNEZ, M.; SÁNCHEZ, J. Resultados de seis años de investigación de cultivo en callejones (alley cropping), en "La Montaña”, Turrialba. El Chasqui, v.19, p.5-24, 1989.

KOECH, E.K.; WHITBREAD, R. Disease incidence and severity on beans in alleys between leucaena hedgerows in Kenya. Agroforestry Systems, v.49, p.85-101, 2000.

McCOLLUN, R.E. Buildup and decline in soil phosphorus: 30-years trends on a typic Umprabuult. Agronomy Journal, v.83, p.77-85, 1991.

McDONALD, M.A.; STEVENS, P.A.; HEALEY, J.R. Soil fertility under Calliandra calothyrsus hedgerows and other land-use treatments following forest clearance in Jamaica. Agroforest Systems, v.57, p.127-135, 2003.

MAFRA, A.L.; MIKLÓS, A.A.W.; VOCURCA, H.L.; HARKALY, A.H.; MENDOZA, E. Produção de fitomassa e atributos químicos do solo sob cultivo em aléias e sob vegetação nativa de cerrado. Revista Brasileira de Ciência do Solo, v.22, p.43-48, 1998.

MAPAONA, S.Y.; KITOU, M. Yield response of cabbage to several tropical green manure legumes incorporated into soil. Soil Science and Plant Nutrition, v.40, p.415-424, 1994.

MATTA-MACHADO, R.P.; NIELY, C.L.; CABRERA, M.L. Plant residue decomposition and nitrogen dynamic in an alley cropping and annual legume-based cropping system. Communications in Soil Science and Plant Analysis, v.25, p.3365-3378, 1994.

OLIVEIRA, F.L. de. Manejo orgânico da cultura do repolho (Brassica oleracea var. capitata): adubação orgânica, adubação verde e consorciação. 2001. 87p. Dissertação (Mestrado) - Universidade Federal Rural do Rio de Janeiro, Seropédica, 2001.

PALADA, M.C.; KANG, B.T.; CLAASSEN, S.L. Effect of alley cropping with Leucaena leucocephala and fertilizer application on yield of vegetable crops. Agroforestry Systems, v.19, p.139-147, 1992.

QUINTON, J.; RODRIGUEZ, F. Impact of live barriers on soil erosion in the Pairumani Sub-cachment, Bolivia. Mountain Research and Development, v.19, p.292-299, 1999.

RILEY, J.; SMYTH, S.A study of alley-cropping data from Northern Brazil. I. Distributional properties. Agroforestry Systems, v.22, p.241-258, 1993.

RITSCHEL, P.S.; VIEIRA, J.V.; PEREIRA, A.S.; PESSOA, H.B.S.V. Avaliação de intensidade e uniformidade da coloração de raízes de cenoura cv. Brasília. Horticultura Brasileira, v.13, p.109-111, 1995.

SOUZA, J.L. Manual de agricultura orgânica: tecnologia para produção de alimentos saudáveis. Emcapa, 1998. p.132-142.

SUDO, A.; GUERRA, J.G.M.; ALMEIDA, D.L. de; RIBEIRO, R. de L.D. Avaliação do consórcio de cenoura com alface em sistema 
orgânico de produção. Seropédica: Embrapa-CNPAB, 1997. 6p. (Comunicado Técnico, 17).

TANGYA; YAN-ZHOU, Z.; JIA-SUI, X.; HUI, S. Incorporation of mulberry in contour hedgerows to increase overall benefits: a case study from Ningnan County, Schuan Province, China. Agricultural Systems, v.76, p.775-785, 2003.

TEDESCO, M.J. Extração simultânea de N, P, K, Ca e Mg em tecidos de plantas por digestão com $\mathrm{H}_{2} \mathrm{O}_{2}-\mathrm{H}_{2} \mathrm{SO}_{4}$. Porto Alegre: UFRGS, 1982. 23p. (Informativo Interno, 01/82).

YAFFA, S.; DAINJU, U.M.; SINGH, B.P.; REDDY, K.C. Fresh market tomato yield and soil nitrogen as affected by tillage, cover cropping, and nitrogen fertilization. HortScience, v.35, p.12581262, 2000.

YAMOAH, C.F.; AGBOOLA, A.A.; WILSON, G.F. Nutrient contribution and maize performance in alley cropping. Agroforestry Systems, v.4, p.239-246, 1986.

ZARAHARAH, A.R.; BAH, A.R.; MWANGE, N.K.; KATHULI, P.; JUMA, P. Management of gliricidia (Gliricidia sepium) residues for improved sweet corn yield in an Ultisol. Nutrient Cycling Agroecosystems, v.54, p.31-39, 1999.

Recebido em 3 de julho de 2003 e aprovado em 7 de junho de 2004 